Editorial

\title{
Letter from the Editors: Special Issue on “Responsibilities of Educators in International Business"
}

\author{
Allan Bird, Guest Editor ${ }^{1}$, Daria Panina, Guest Editor², William Newburry, Associate Editor ${ }^{3}$ \\ ${ }^{1}$ Northeastern University, USA, ${ }^{2}$ Texas A\&M University, USA, ${ }^{3}$ Florida International University, USA \\ Keywords: international business education, capabilities, global citizenship
}

\section{AIB Insights}

Vol. 20, Issue 1, 2020

\begin{abstract}
Working in cooperation with the AIB Teaching and Education Shared Interest Group and the Consortium for Undergraduate International Business Education, this focused issue of AIB Insights seeks to flesh out the contours of responsible IB education and promote a dialogue about enhancing the quality of IB education through an acceptance of greater accountability. The eight articles in the issue help us to better understand the responsibilities of educators in international business, while also proscribing actions we can pursue to achieve this important goal.
\end{abstract}

At a time when international business scholars have called on executives and managers to place greater attention on corporate social responsibility in order to address issues of inequality, diversity, inclusion, and sustainability, in line with Rasche and Gilbert's (2015) broader call, it is appropriate for the academic community to turn its attention inward and address the issue of responsibility in international business education. Given the expansion of IB educational activities through increasing coverage of relevant topics in functional courses, what is the role of IB education in shaping the mindsets and values of the business leaders of tomorrow? What is the unique contribution of IB courses to transforming business students into citizens of the world? In short, what responsibility do international business educators have and what do they aspire to achieve as educators?

Several aspects of IB education raise distinctive issues when addressing matters related to educator responsibility. It is not uncommon, for instance, for educators to seek not just education, but transformation. This has given rise to increasing use of experiential learning approaches (Taras \& Gonzalez-Perez, 2015), particularly in cross-cultural management courses. In 2014, AIB Insights (Maznevski, 2014; Peterson, 2014) dedicated an issue to one instance of an experiential activity that went terribly wrong, thereby plunging students, the instructor, and the institution into turmoil. What responsibility do instructors and institutions have in the selection and implementation of different pedagogies? To what extent do IB educators consider the impact their instructional decisions may have on their students, institutions of higher education, and the world?

In a similar vein, in a time of instability in sociopolitical and economic structures on the global level (Meyer, 2017) - amid calls for de-globalization and appeals to reconsider capitalism - what role does IB education play in promoting and maintaining civility, rationality, and dialogue in the broader public square?

Realizing the importance of better understanding the responsibilities of educators in international business, this focused issue of AIB Insights addresses topics such as those highlighted above. We seek to further flesh out the contours of responsible IB education and promote a dialogue about enhancing the quality of IB education through an acceptance of greater accountability.

The issue has been developed by a team of editors, with AIB Insights Associate Editor William Newburry working in cooperation with two important organizations in the field of IB education: the AIB Teaching and Education Shared Interest Group (AIB T\&E SIG) and the Consortium for Undergraduate International Business Education (CUIBE). The AIB Teaching \& Education SIG focuses on promoting excellence in IB teaching. Its main objectives are facilitating development and sharing of best teaching practices, providing a forum for teaching-related networking, exchange of ideas and mentoring, and promoting research on teaching and education among AIB members. To this end, the Teaching \& Education SIG provides AIB members with a worldwide forum for scholarly engagement concentrated on teaching methods, maintains a repository of knowledge for AIB members on diversity and recent trends in teaching methods, stimulates innovation and promotes the use of new teaching tools, methods and approaches, and organizes professional development opportunities for AIB members on the topic of teaching and education. The SIG's founding Chair, Daria Panina, served as a Guest Editor of this issue.

The Consortium for Undergraduate International Business Education (CUIBE) was established in 2003 to promote, enhance, and foster innovations in the delivery of international business education. Currently, the consortium includes 42 universities (25 full-members and 17 associate members). More than half of the universities currently ranked among US News \& World Reports' top undergraduate IB programs are CUIBE members. While originally constituted only of US universities, recent international new members include the University of Leeds (U.K.) and the Universidad de la Sabana and EAFIT Universidad (Colombia). The primary objectives of CUIBE are to provide its members with an opportunity to benchmark their programs against other member schools and to facilitate sharing of best practices in IB education. CUIBE also sponsors the CUIBE Award for Best Paper on International Business Education at the annual AIB Meeting. Allan Bird, one of the founding architects of CUIBE, served as a Guest Editor of this special issue. Additional information on CUIBE can be found at: https://cuibe.net/

Examining the content of this special issue, the introductory article, by Jose de la Torre and Corinne Young, seeks to overview some of the historical antecedents and foundations of thought on global citizenship and business education. They note that the rights, duties, and obligations of a citizen of any sovereign state are still fundamental to civil society, and that the interconnectedness of today's 
world requires us to recognize that these rights and obligations may no longer be confined within national boundaries and that many global issues require global civic responses. They raise questions such as: How should global citizenship be defined? Wherefrom does it derive its legitimacy? What does it mean for business leaders? How can it be taught and promoted? The authors address the first two of these questions in this article; a companion piece occurring later in this issue will attempt to answer the other two.

The second article, by Jörg Hruby, Cyntia Vilasboas Calixto and Umesh Mukhi, builds upon the introductory article and proposes a theoretical framework to provide an overall macro-micro level perspective on the various antecedents and outcomes that may directly or indirectly relate to teaching, research and institutional practices of the IB community. The authors note that their study is designed to open a dialogue among IB scholars and educational institutions as well as provide insights focusing on the nature of responsibility in IB teaching, the factors influencing this learning process, and learning outcomes for IB students and instructors alike.

The third article, by Nancy Buchan, Elizabeth Ravlin and Orgul Demet Ozturk, first discusses how IB educators shaped their curricula in response to rapid globalization before the financial crisis of 2008. The authors then utilize the $\mathrm{O}^{*} \mathrm{NET}$ database and employment statistics provided by American Community Survey and Census Data to examine trends in different skill sets required in the workplace. The paper concludes that the post-2008 stage of globalization is characterized by a shift towards the importance of nonroutine analytical capabilities, global interpersonal skills, and experiential skills as it addresses what implications this new phase of globalization may have for IB education, how to tackle its challenges, harness its opportunities, and prepare our students for this new world.

The fourth article in this issue, by Yongsun Paik, examines the value of international business education and how to achieve transformative learning. The article aims to achieve this goal by addressing three key questions confronted by international business educators: Why should international business courses be taught? What needs to be taught? and How should these courses be taught? In the course of examining these questions, the article identifies three education dimensions: Developing Global Leaders and Citizens, Obtaining Comprehensive Understanding of Different Disciplines, and Achieving Transformative Learning, while also providing actionable recommendations for each dimension.

The fifth article, by Astrid Schmidt-King, discusses the potential value of high-impact practices (HIPs) to International Business (IB) education, especially at a time when IB educators need to think and act strategically. She notes that deglobalization or anti-globalization sentiments do not signal a time to retreat for IB educators, but rather they provide IB education with a rare opportunity to showcase its relevancy as a discipline and our responsibility as educators of global leaders. Dr. Schmidt-King challenges IB educators to rethink and reassess existing resources that can be used to meet this objective. The article examines the intrinsic value of IB's interdisciplinary nature and its important relationship with globalization. It then explores two HIPs e-portfolios and capstone projects - that are uniquely positioned to enhance and showcase the inherent transforma- tive nature of IB learning and highlight its distinct pedagogical approach.

Our sixth article, by David Berg, focuses on preparing students for the changing global environment by examining the responsibilities of educators to choose the most appropriate tools available in international business teaching. One of our responsibilities and roles as international business educators and scholars is to help prepare students to work effectively in a variety of business environments and to provide them with the necessary tools to operate in changing circumstances. We do this, in part, by encouraging the development of a global mindset, a sense of global citizenship, and critical thinking capabilities, even as the nature of what 'global' means fluctuates. This article addresses this need by first examining what makes international business education distinctive and what it means to be a global citizen. The article then overviews several experiential exercises that can be used in the classroom as tools for international business education.

Our seventh article in this issue, by Donna Cooke, Frank DuBois, Rajeev Sawant, David Sprott and Len Treviño, notes that a more structured effort to educate students on both the benefits and drawbacks or "dark side" of IB is warranted. The authors contend that dark side activities (DSA) should be positioned as a more central component of IB coursework so that students can understand the legitimacy and performance consequences of such phenomena. They draw on six types of DSA with which MNEs may be directly or indirectly involved. Among them are environmental degradation; questionable marketing practices; accounting or financial fraud; corruption; labor abuses; and cultural imperialism (Batra, 2007). The authors argue that it is incumbent on IB educators to expose IB students to concrete examples that illustrate when international business drifts to the dark side. The article provides two short case study examples that can be used to illuminate cultural differences, corruption, varying ethical norms, CSR and sustainability within DSA. The authors then provide a series of informational resources and discussion prompts for one of the most horrific sides of international business - namely human trafficking. They conclude by outlining a potential framework from the UN that can be used to structure in-class discussion of DSA.

Our final article, by Jose de la Torre and Corinne Young, builds upon the issue's first article by examining practices that business schools are currently pursuing to train executives to become global citizens, while also identifying areas where the authors perceive greater effort is needed. The authors overview some early efforts by business schools to promote the teaching of global citizenship in line with the goals of the UN Global Compact based on Principles for Responsible Management Education and a study of such efforts by the Aspen Institute. The authors then discuss "What Next?" and examine some recent efforts by business schools, while also noting the challenge to rethink global management education, a challenge brought to the forefront by the current Covid-19 pandemic.

Overall, we hope you find that this special issue of $A I B$ Insights provides guidance in addressing important issues related to the responsibilities of educators in international business, while also encouraging additional pedagogical development. 


\section{REFERENCES}

Batra, M. M. 2007. The dark side of international business. Competition Forum, 5(1): 306-314.

Maznevski, M. 2014. Managing Deep Intercultural Training Exercises. AIB Insights, 14(2): 7.

Meyer, K. E. 2017. International business in an era of anti-globalization. Multinational Business Review, 25(2): 78-90.
Peterson, M. F. 2014. Stepping on cultural and religious assumptions. AIB Insights, 14(2): 4.

Rasche, A., \& Gilbert, D. U. 2015. Decoupling responsible management education: Why business schools may not walk their talk. Journal of Management Inquiry, 24(3): 239-252.

Taras, V., \& Gonzalez-Perez, M. A. (Eds.). 2015. The Palgrave handbook of experiential learning in international business. London: Palgrave Macmillan. 